\begin{tabular}{ll}
\hline POLITEIA & POLITEIA: Jurnal Ilmu Politik \\
Politeia, 14 (1) (2022): 32-41 \\
ISSN (Print), ISSN (Online) \\
Available online https://jurnal.usu.ac.id/index.php/politeia \\
\hline
\end{tabular}

\title{
Demokrasi Radikal Sebagai Alternatif Tatanan Politik Global dalam Konteks Multikulturalisme
}

\author{
Dewi Setiyaningsih*
}

Program Magister Ilmu Hubungan Internasional, Universitas Gadjah Mada, Daerah
Istimewa Yogyakarta 55281
Submitted : 08 Agustus 2021 Revision : 18 Desember 2021 Accepted : 10 Januari 2022

\begin{abstract}
Abstrak
Artikel ini membahas tentang relevansi konsep demokrasi kosmopolitan dalam dunia multikultural. Artikel ini berpendapat bahwa konsep demokrasi kosmopolitan tidak cukup dalam mencapai tatanan politik yang adil dan setara dalam konteks kewargaan dunia yang plural, hal ini ditunjukkan oleh praktik struktur ekonomi, sosial dan politik yang berlaku. Oleh karena itu, artikel ini mencoba mencari alternatif dalam upaya membuat gagasan demokrasi kosmopolitan menjadi lebih realistis dan inklusif dengan mengadopsi konsep demokrasi radikal. Pertama, membahas kritik terhadap pandangan kosmopolitan Kant dengan menggunakan konsepsi Spivak tentang Planetaritas. oleh Mouffe dalam konteks planetaritas. Kombinasi inilah yang menghasilkan demokrasi plural dalam konteks kewargaan dunia.

Kata Kunci: demokrasi radikal, kosmopolitanisme, kewarganegaraan dunia, politik global.
\end{abstract}

\begin{abstract}
Abstrak
This article discusses the relevancy of cosmopolitan democracy concept in multicultural world.It argues that cosmopolitan democracy concept is not enough in achieving a just and equal political order the context ofplural world-citizenship, it showed by the practice of economic, social and political structure which prevails. Hence, this articletried to search an alternative in attempt to make the idea of cosmopolitan democracy become more realistic and inclusiveby adopting radical democracy concept.Firstly, it discuss the critics of Kant's cosmopolitanview using Spivak's conception of Planetarity.Secondly, it discuss about the plural democracy by Mouffe's in the context of planetarity. This combinationthat yields a plural democracy in the context of world-citizenship
\end{abstract}

Keyword: radical democracy,cosmopolitanism,world citizenship, global politics

How to Cite: Setyaningsih, D. (2021). Demokrasi Radikal Sebagai Alternatif Tatanan Politik Global dalam Konteks Multikulturalisme. Politeia : Jurnal Ilmu Politik, 14 (1): 32-41.

\footnotetext{
${ }^{*}$ Corresponding author:

E-mail: rizkimaqbul@gmail.com
} 


\section{PENDAHULUAN}

Berakhirnya perang dingin telah merubah tatanan dunia dan menghasilkan sebuah dunia baru yang jamak disebut globalisasi. Hal ini juga membuat kajian-kajian disiplin ilmu politik berkembang dalam upayanya merespon fenomena-fenomena yang dihasilkan oleh perubahan tersebut, salah satunya contohnya adalah lahirnya konsep kosmopolitanisme. Dalam konsep kosmopolitanisme, pemetaan negara-bangsa yang memusatkan dirinya pada aspek kedaulatan dianggap mulai terkikis seiring dengan lahirnya aktor-aktor yang mengidentitaskan dirinya di luar negara-bangsa, yang mana juga merupakan tantangan tersendiribagi konsepkedaulatan. Ditopang dengan banyaknya persoalan kemanusiaan yang sifatnya transnasional, aktoraktor non negara mulai memprioritaskan norma-norma kemanusiaan diatas kedaulatan negarabangsa.

Kosmopolitnisme juga lahir untuk sebuah tujuan mulia, yaitu menghadirkan demokrasi dalam tatanan dunia.Dari segi politik, demokrasi yang diwarisi dari era pencerahan pun dianggap hanya mampu terselenggara di tingkat negara bangsa sementara tidak terjadi di level global. Hal tersebutdisebabkan olehkepentingan masing-masing negara ketika berinteraksi di level global, yang mana tercermin dalam perang dunia. Dalam konteks ini, ide kosmopolitan tidak hanya terbit untuk wacana membangun norma keadilan dan kemanusiaan universal,melainkan juga konsepsi demokrasi global.

Akan tetapi, gagasan kosmopolitanisme tersebut rupanya menuai kritik tatkala terlalu mendasarkan diri pada model globalisasi yang sebenarnya merupakan warisan dari hegemoni perang dunia. Begitu pula, ketika ia ditarik dalam wacana demokrasi, atau yang disebut demokrasi kosmopolitan. Demokrasi kosmopolitan yang mendasarkan diri pada model globalisasi dipandang oleh Mouffe (Mouffe, 2008)merupakan sebuah proyek ambisius yang hegemonik karena menganggap sistem dunia bersifat unipolar, bukan multipolar.

Salah satu struktur yang mencerminkan gagasan unipolar ini dapat diidentifikasi dari adanya rezim-rezim

internasional.

Negara-negara berkembang bekas jajahandianggap lebih terbelakang dan menjadi objek pengadaan program-program pembangunan oleh negara yang dianggap secara kapital lebih mapan.Negara-negara berkembang diteliti dan dihitung perkembangan proyeknyadengan ukuran konsepsi pembangunan berperspektif negara maj sehingga menghilangkan aspek lokalitasnya.Narasi-narasi

pembangunan demikian ini yang disebut bersifat hegemonik.Identitas kultural dan nilai-nilai lokal menjadi semakin kabur akibat modernisasi yang merupakan buah gagasan globalisasi (Sharp, 2004).Atas dasar tersebut, makalah ini berupaya merumuskan ulang konsep demokrasi radikal yang bisa diterapkan dalam tatanan dunia dengan mengkaji ulang pemikiran-pemikiran mengenai tatanan demokrasi radikal dan kosmopolitanisme 


\section{METODE PENELITIAN}

Makalah ini merupakan kajian teoritis yang mengkaji pemikiran ilmuanilmuan dalam hal demokrasi dan konsmopolitanisme global. Dengan begitu, metode analisis yang digunakan adalah analisis kualitatif.Sumber yang digunakan adalah literatur-literaur dari karya orisinil para pemikir, baik berupa buku-buku maupun jurnal.

Tulisan ini menggunakan pendekatan kritis yang dikembangkan oleh Chantal Mouffe tentang demokrasi radikal (2009) dan konsep Planetaritas yang dikembangkan oleh Gayatri Spivak (Spivak G. The Death of Discipline, 2003). Penulis menggunakangagasanSpivak mengenai kritiknya terhadap globalisasi yang dijadikan landasan dalam bangunan kosmopolitanisme dan pandangan Mouffe mengenai demokrasi radikal dalam membuat tawaran konsep demokrasi yang lebih realistis dalam pluralitas dunia. Dengan kata lain, tulisan ini menawarkan sebuah landasan baru dalam memakanai konsep tatanan dunia, bukan dengan merujuk pada konsep globalisasi, melainkan konsep Planetaritas yang dikembangkan oleh Gyatri Spivak. Sedangkanuntuk merumuskan landasan demokrasi kosmopolitan, makalah ini merujuk pada pandangan demokrasi radikal Mouffe.

Konsep planetaritas dikembangkan oleh Gayatri Spivak dalam rangka upayanya membangun kritik terhadap sistem globalisasi yang kerap menimbulkan problem-problem ketimpangan struktural dan dominasi budaya akan suatu komunitas negara dan masyarakatnya. Sementaara demokrasi radikal adalah konsep yang dikembangkan oleh Chantal Mouffe untuk mengkritik praktik demokrasi di sebuah negara ataupun dunia yang sekedar elektoral dan prosedural, namun secara prinsipil hanya menjadi agenda bagi sekelompok elit sehingga mengabaikan suara-suara yang tertindas (Mouffe, 2008).

\section{HASIL DAN PEMBAHASAN}

\section{Problem Kosmopolitanisme dalam Masyarakat yang Multikultur}

Sejak berakhirnya perang dingin dan datangnya globalisasi, kosmopolitanisme dengan ide-idenya tentang keadilan global dan kewarganegaraan lantas menjadi trend politik.Konsmopolitanismemenjadi

gagasan arus utamakeadilan pascaperang dingin karena pandangannya yang menjanjikan mengenai individu yang merupakan bagian dari tatanan yang setara dan bukan dari seperangkat adat atau tradisi tertentu.Kepercayaan ini mengasumsikan bahwa perdamaian di antara negara-bangsa hanya mungkin jika mereka melampaui identitas dan kepentingan parokial mereka atas nama negara atau kesadaran global. Hal ini membuat kosmopolitanisme tampak demokratis dalam semangatnya(Trepanier, 2011).

Sementara itu, kosmopolitanisme muncul di kalangan masyarakat awam sebagai akibat dari perubahan praktik kehidupan seharihari yang semakin banyak mengandung benda-benda budaya asing dan idiom yang sebagian besar didorong oleh mediamassa, yaitu "kapitalisme cetak" (Anderson, 2016).

Secara filosofis, kosmopolitanisme mendapati akarnya dari tradisi yunani kuno, lebih spesifiknya pada tradisi Stoic, yakni era Herraclitus, Epikurus, Permenides. Cerita awal yang terkenal pada waktu itu Cynic ditanya oleh seorang kawan, "Warga manakah Anda?". Lalu ia menjawab "warga dunia". Inilah awal mula gagasan kosmopolitanisme yang lalu menjadi prinsip dan berkembang menjadi 
konsep politik hari ini. Oleh Socrates, mengangkat kasus refugee di gagasan cosmo politea tersebut Perancis.Dalam kasus tersebut, terbukti berkembang. Nusbaum (1997) bahwa keramahtamahan yang menjelaskan bahwa Kant mewarisi dipopulerkan oleh Kant sebenarnya banyak gagasan Stoic ini untuk terbatas pada bangunan konsepsi mengembangkan konsep perptual peace negara bangsa, karena refugee yang nya, salah satunya mengadopsi natural dianggap sebagai stateless akhirnya law Cicero. Kant lebih terkenal sebagai tidak memiliki hak atas hidup ataupun kalangan pencerahan karena gagasan mendapat keramahtamahan universal kosmopolitnya berlandaskan nalar dan karena statusnya yang tidak dibawah etika reformatif dan optimis ketimbang negara-bangsa (Derrida, 1997). para communitarian (Nussbaum, 1997). Konsepsi kosmopolitanisme pada Kosmopolitanisme versi Kant ini juga akhirnya hanya melingkupi negara yang sering dimaknai sebagai bangsa dan meniadakan entitas-entitas kosmopolitan pencerahan (enlightment lainnya. cosmopolitanism) dan banyak disepakati secara umum karena prinsip-prinsip keramahtamahan universalismenya.

Ada tiga elemen yang saling terkait yang terlibat dalam aspek kosmopolitanisme

Kant.Pertama, individu mewakili unit perhatian moral tertinggi secara setara dan bahwa kapasitas manusiawi kita hanya dapat berkembang dalam kondisi keadilan universal.Kedua, pencapaian keadilan universal membutuhkan pengembangan yang lebih luas dari masyarakat sipil kosmopolitan, yang hanya didasarkan pada kemanusiaan kita sendiri, tanpa mengacu pada kebangsaan, afiliasi politik lokal, atau tempat lahir.Ketiga, satu-satunya perhatian hukum kosmopolitan adalah dengan menetapkan matriks keadilan universal ini dan merumuskan prinsipprinsip normatif fundamental yang diperlukan dalam menopang konstitusi kosmopolitan (Brown G. W., 2009).

Namun, pandangan Kant tersebut terlalu mengedepankan sisi moral dan etika sehingga naif akan realitas dan tatanan politikglobal yang berkembang. Derrida (1997) mengkritik kosmopolitanisme Kant pada keramahtamahan universalnya dengan

Permasalahan lain yang ada pada gagasan kosmopolitanisme Kant adalah konsep globalisasi yang lahir diera modern yang cenderung melihat sistem dan tatanan global yang ada sebagaitaken for grantedatau secara bebas-nilai. Implikasi dari asumsi ini,lembaga-lembaga internasional yang ada dianggap sebagai representasi demokrasi kosmopolitanisme semata dan demi menjaga terlaksananya nilai-nilai moralitas. Hal inilah yang perlu diperbaiki dari pandangan kosmopolitanisme abad pencerahan, yaitu pada sisi bagiamana memandang dunia.

Spivak(2012) menyebut kosmopolitanisme abad pencerahan tersebut sebagai proyek "kosmopolitik". Ia merujuk pada pengertiancosmo yang bermakna dunia danpolithea, berasumber dari buku Res Republika Plato yang bermakna "kosntitusi". Maka, yang terjadi dalam konsep politik kosmopolitanisme adalah kepengaturan dunia, dimana ia cenderung bersifat hegemonik. Oleh karenanya, Spivak berasumsi bahwa pemikiran Kant (1963) mengenai cosmopolitheia berkaitan erat dengan 
munculnya monopoli kolonialisme kapitalis. Sebagai hasil dari kolonisasi yang tumbuh oleh tuntutan ekspansi kapitalisme industri, para generasi Kant tersebut merupakan hasil dari masyarakat kapitalisme global yang memiliki akses kepada "duniaglobal" (Spivak G. C., 2012)

Perbedaan gagasan Kant dengan Palto adalah pada ruang lingkup yang diamati. Kant sebagai intlektual Eropa kontemporer memiliki dunia sebagai realitas sosial yang ditinggali dan diamati,sementara Plato hanya terbatas pada negarakota.Gagasan keduanya bisa dikatakan seperti evolusi dari politheia menuju ke kosmopolitheia, konstitusionalitas pemerintahan bagaimanapun, mengkritik bahwa dan

dari menuju dunia.Namun, kosmopolitik Kant tidak dapat melampaui negara-bangsa.Sementara menurut Spivak (Spivak G. C., 2012) kosmopolitanisme Kantsangat bersifat regional, yakni Eropa.Spivak menunjukkan bahwa ada kosmopolitanisme di Asia atau selain Eropa.

Implikasi dari pandangan

kosmopolitan yang melandaskan pada pandangan globalisasi adalah munculnya konsep demokrasi kosmopolitan. Demokrasi kosmopolitan ini tidak menyebabkan sentralitas kepengaturan dunia dapat bersifat lebih adil dan inklusif selama ia mendasarkan pada sistem globalisasi.

Held (2001) menelusuri kebutuhan akan terciptanya demokrasi kosmopolitan dari peerkmbangan komunitas politik sejak era Yunani Kuno hingga Post-Westphalia (globalisasi). Menurutnya, terdapat implikasi globalisasi pada komunitas politik, antara lain: (1) lokus kekuasaan politik yang efektif tidak lagi dapat dianggap dalam lingkup pemerintah nasional, kekuatan efektif dibagi, ditukar, dan diperebutkan oleh berbagai kekuatan dan lembaga di tingkat nasional, regional dan internasional. (2) Gagasan sebuah komunitas politik sebagai penentuan nasib sendiri tidak dapat lagi berada di dalam batas-batas satu negara tunggal saja. (3) Ada wilayah yang signifikan yang ditandai dengan loyalitas, yang mana menggantikan pengertian "wilayah" kedaulatan sebagai bentuk kekuasaan publik yang tidak terbatas, tidak dapat dipisah, dan eksklusif. Komunitas politik ini lalu memiliki tuntutan bermacam-macam atas keterbatasan sistem kedaulatan Westphalia, sehingga dalam hal ini demokrasi justru memiliki prospek yang lebih luas yaitu dengan adanya demokrasi kosmopolitan.

Held (2001) juga memandang dunia kontemporer memerlukan penerapan hukum yang sifatnya demokratik-kosmopolitan dan pembentukan komunitas politik melalui kewajiban untuk membangun struktur aksi politik transnasional agar dapat mendukung politik penentuan nasib sendiri. Tetapi ini tidak berarti bahwa negara-negara dan pemerintahan demokratis nasional menjadi sia-sia.Sebaliknya, membuat negara tidak bisa lagi dianggap sebagai pusat tunggal kekuasaan yang sah dalam batas-batas yang dibuat sendiri. Negara-negara perlu diartikulasikan dalam sebuah hukum demokrasi yang menyeluruh. Pandangan Held sarat akan prinsip demokrasi liberal yang mana seluruh pihak yang disebut 
sebagai komunitas politik dianggap memiliki kekuatan politik yang sama.

Sementara praktinya, perangkat politik yang paling besar tetap dimiliki oleh negara, sementara dalam tatanan global, dominasi atas instrumen politik berupa lembaga-lembaga multilateral berada dibawah kekuatan hegemonik. Kosmopolitanisme abad pencerahan mampu diperbaiki dengan cara memberi pandangan alternatif mengenai dunia, bukan dalam lensa globalisasi yang menjadikan pandangan mengenai dunia terintegrasi menjadi satu entitas unipolar. Melihat fakta bahwa dunia memiliki isi yang begitu beragam dengan sistemnya masing-masing, pandangan terhadap dunia yang lebih multikultural sangat diperlukan. Pandangan semacam ini salah satunya telah di sumbang oleh Appiah (2006).

Menurutnya, kosmopolitanisme merupakan rasa tanggung jawab kepada semua manusia, menghargai kehidupan sekalipun kepada kehidupan orang yang asing dan memiliki rasa ingin tahu tentang kekhasan budaya orang lain. Secara singkat, kosmopolitanisme adalah perhatian universal dan rasa hormat terhadap orang lain.Menurutnya lagi, kosmopolitanisme sebagai pandangan dunia jauh lebih memuliakan, universal, dan integratif ketimbang pandangan-pandangan lainnya di era modern. Hal ini karena pandangan kosmopolitanisme mewajibkan setiap individu memiliki tanggungjawab untuk saling mengetahui melalui percakapan lintas budaya.

Gagasan tersebut sebangun dengan konsep planetaritas yang digagas oleh Spivak (2003). Baginya, asumsi mengenai planet sebagai tempat tinggal akan lebih terbuka dalam menerima taksonomi yang tidak ada habis-habisnya dari entitas dunia, termasuk yang tidak identik dengan ajaran universal manusia, misalnya animisme aborigin serta mitologi putih dari ilmu postrasional.Membayangkan individu sebagai subyek planet ketimbang agen globalisasi, makhluk planet ketimbang entitas global, akan menyebabkan dunia terdiri dari keberagaman (alterity)tanpa perlu dinegasikan demi membentuk atau mencari kesamaannya. Namun, pandangan demikian menurutnya hanya mampu diperoleh jika individu tidak mendasarkan diri pada globalisasi, yang terdiri dari sistem kapitalisme global, teknologi informasi yang berkembang namun menjauh dari etika dan esensi dasar manusia.

Globalisasi telah membuat dunia menjadi selembar peta dan sebuah bola globe yang lalu terkomputerisasi. Oleh karena itu, planetaritasdalam pemahaman Spivaksangat cocok dibayangkan dalam konteks budaya prakapitalis planet ini(Spivak G. , The Death of Discipline, 2003).

Spivak memberikan tawaran berupa studi komparatif dengan tujuan agar tidak ada dominasi budaya, misalnya penggunaan bahasa. Menurutnya kekayaan bahasa di dunia tidak seharusnya dihilangkan karena bahasa merupakan medium memasuki kelompok-kelompok yang berbeda. Secara epistemologi, Spivak menawarkan pendekatan historis yang disebut 'perang budaya' sebagai kritik terhadap pendekatan Eurocentrism, pendekatan modernitas vis a vis tradisi (Spivak G. C., 2012).

Dengan begitu, melalui gagasan planetaritas, Spivak tidak bermaksud bersifat komunitarian ataupun 
sinkretis, akan tetapi berniat mengubah pandangan kosmopolitan yang berbasis paradigma globalisasi menjadi pandangan kosmopolitan yang lebih radikal.

Demokrasi Radikal sebagai Alternatif Politik Global

Banyaknya

pembahasan

'kewarganegaraan' dan 'komunitas' merupakan konsekuensi dari krisis politik kelas dan menunjukkan tumbuhnya kesadaran akan perlunya suatu bentuk identifikasi baru untuk mengorganisir kekuatan-kekuatan yang berjuang untuk radikalisasi demokrasi. Identitas politik memang sangat penting dan upaya untuk membangun identitas warga (citizenship) harus menjadi salah tujuan dari politik demokrasi.Namun, ada banyak visi berbeda tentang kewarganegaraan dan isu-isu sentral yang dipertaruhkan.Bagaimana definisi kewarganegaraan tidak terlepas dari jenis masyarakat dan komunitas politik yang diinginkan pandangan tertentu. Demokrasi radikal memahami kewarganegaraan membutuhkan rantai kesetaraan di antara perjuangan demokratis, sehingga tercipta identitas politik bersama di antara subyek demokratis.Oleh karenanya, demokrasi radikal melampaui konsepsi kewarganegaraan dari tradisi republikan liberal dan sipil sambil membangun kekuatan masing-masing (Mouffe, 2013).

Held(1995;

2001)juga

menawarkan demokrasi kosmopolitan yang merupakan proyek teori politik normatif yang berusaha menerapkan beberapa prinsip, nilai dan prosedur demokrasi ke sistem politik global. Ia berpijak pada sejarah jatuhnya Tembok
Berlin sebagai tanda dimulainya rezim demokratis yang menyebar di Timur dan Selatan. Meskipun tidak semua rezim ini sama-sama menghormati hak asasi manusia, ada tekanan yang signifikan untuk mencapai pemerintahan yang representatif, bertanggung jawab dan sah.

$$
\text { Archibugi \& Held(1995) }
$$

beranggapan kemenangan liberalisme seharusnya mampu menghasilkan perkembangan demokrasi sebagaimanacara dalam pemerintahan global. Namun, aturan sistem internasional justru tidak menjalankan prosedur demokratis, akan tetapi lebih kepada kekuatan dan kepentingan relatif dari aktor-aktor.Hal ini terkesan kontradiktif, bahwa demokrasi dianggap sebagai sistem politik universal dari era globalisasi tetapi globalisasi justru tidak diperintah sesuai dengan nilai-nilai demokrasi.Inilah yang menjadi pemicu lahirnya demokrasi kosmopolitan. Maka, demokrasi kosmopolitan adalah upaya untuk mewujudkan demokratisasi di negara-negara sekaligus menerapkannyadi level internasional yang mana dilakuakn oleh berbagai kelompok politik (Archibugi, 1995).

Hal tersebut yang diupayakan oleh Archibugi, yakni menerapkan demokrasi kosmopolitan dalam globalisasi. Maka, demokrasi global tidak dapat dibayangkan sebagai akibat langsung dari demokrasi di negara-negara bagian, namun, dibutuhkan penciptaan prosedur dan institusi khusus yang akan menambah tingkat perwakilan politik ke lembaga yang sudah ada.

Archibugi dan Held tetap mendukung adanya negara-bangsa dan mereka mengungkapkan bahwa keterwakilan 
di tingkat global akan menajga fungsi individu dan hak-hak universal, dan administrasi politik negara-negara. demokrasi yang mengistimewakan Mouffe meanfsirkan bahwa demokrasi gagasan persamaan dan 'pemerintahan kosmopolitan dalam kerangka oleh rakyat', yaitu kedaulatan rakyat. Archibugi dan Held semata-mata Artikulasi seperti ini bukanlah suatu bertujuan untuk meningkatkan tata keharusan, tetapi sebuah produk dari kelola masyarakat. Revolusi semacam sejarah tertentu.

ini dilakukan melalui pembentukan lembaga-lembaga internasional yang memungkinkan individu untuk memiliki pengaruh pada urusan global, terlepas dari situasi di negara mereka sendiri. Tuntutan semua individu, terlepas dari asal kebangsaan mereka, kelas, gender, dll.

Mouffe (2009) memandang skeptis pada pendekatan demokrasi kosmopolitik tersebut. Ia mealandaskan argumentasi bahwa hak kosmopolitan adalah fiktif karena para individu yang dijemabtani oleh lemabaga-lembaga buatan sesungguhnya berada di luar kendali subjek.Pendekatan kosmopolitik lebih menekankan pada fungsi hak asasi manusia yang melegitimasi daripada pada praktik demokratis sesungguhnya, maka, pembangunan kosmopolitan dari warga dunia(global)semata-mata merupakan bagian dari upaya mengistimewakan moralitas politik. Masalah lain adalah hak-hak kedaulatan pun dikorbankan sebagai imbalan atas hak-hak baru yang fiktif tersebut. Dengan kata lain, kekuatan masyarakat global dapat dikooptasi oleh kekuata hegemonik untuk melemahkan kedaulatan nasional. Selain itu, demokrasi kosmopolitan hanya akan menghasilkan diadopsinya model demokrasi liberal di seluruh dunia.

Demokrasi liberal mengandung paradoks karena terdiri dari dua tradisi yang berbeda: liberalisme, dengan penekanannya pada kebebasan Pandangan dominan dalam berbagai arus teori politik mengenai keharusan penerimaan model demokrasi liberal Barat sebagai satusatunya pengimplementasian HAM harus ditolak tanpa membuang gagasan hak asasi manusia dengan cara yang memungkinkan interpretasi pluralisme. Bagaimana demokrasi bisa diterapkan dalam konteks duni yang multipolar? Mouffe menegaskan bahwa dunia multipolar tidak akan selalu menjadi negara demokratis. Namun, demokrasi di dunia multipolar bisa mengambil berbagai bentuk, sesuai konteks (Mouffe, 2009).

Dalam memberi tawaran demokrasi, Mouffe(2008) mula-mula berkaca pada gagasan HAM universal yang menurutnya menemui masalah ketika dihadapkan pada fakta dunia yang terdiri dari macam-macam kultur. Gagasan HAM tersebut tumbuh subur dalam konteks globalisasi yang membutuhkan legitimasi moralitas politik, hingga akhirnya lahirlah tatanan demokrasi liberal. Merujuk pada gagasan Panikkar, hal tersebut disebut homoemorphic, yaitu kondisi homogenitas gagasan dan kultur yang meniadakan otonomi kultural dan identitas beragam individu. Di titik tersebut, gagasan demokrasi radikal mencoba memandang dunia berada dalam tatanan yang multipolar.Dengan demikian, HAM harus dimaknai secara multikultur agar proyek demokrasi dapat bersifat lebih emansipatoris. Inilah yang disebut kosmopolitanisme 
dari bawah, agendanya berupa menyatukan pihak-pihak yang tersisih oleh universalisme globalisasi,dengan demikian akan berdampak pada pengakuan HAM secara multikultur atau anti-universalisme.

Bagi Mouffe (2008) untuk menciptakan tatanan demokrasi yang plural dalam konteks HAM tersebut, konflik atau antagonisme justru merupakan prasyarat dari terciptanya demokrasi. Mouffe tidak membayangkan demokrasi sebagai cita-cita politik berwujud konsensus atau sebuah babak pencapaian seperti yang dibayangkan oleh Held (2001). Justru demokrasi merupakan ruang kontestasi yang penuh antagonisme, maka, mreka yang berupaya menghindari konflik dengan meniadakan pluaralitas adalah orangorang yang naif akan adanya politik konstitutif/hegemoni, karena agenda dari demokrasi searusnya melegitimasi pluralitas.Laclau dan Mouffe berpendapat bahwa demokrasi radikal merupakan jalan terbaik menuju perubahan sosial progresif lantaran demokrasi radikal meliputi banyak aspek dari tradisi sosialis, bahkan juga mengambil momen-momen paling progresif dari tradisi demokrasi liberal, seperti anti-rasis, anti-seks, antihomofobia, dan lingkungan (Smith, 1998).

\section{SIMPULAN}

Baik Spivak dan Mouffe memiliki kesamaan cara pandang dalam mengkonstruksi makna kosmopolitan, keduanya pun sama-sama bertolak dari pandangan era pencerahan. Spivak membuat konsepsi planetaritas untuk menegubah cara memandang dunia kosmopolitan secara radikal, namun ia tidak memiliki proyek politik yang
jelas.Konsep planetaritas Spivak yang memandang dunia secara multipolar ini lebih tapat menadi landasan dalam memandang dunia ketimbang konsep globalisasi yang mengabaikan keberagaman warga dunia karena mendisiplinkannya pada satu agenda kemajuan modern.Dengan memandang dunia secara planteriat, maka demokrasi radikal yang dikembangkan oleh Mouffe selaras untuk diterapkan.Dengan kata lain, gagasan Spivak mengeanai pluralitas global sebenarnya mendukung gagasan Mouffe dalam menciptakan rumusan demokrasi radikal. Dimana demokrasi radikal itu tidak hanya terjadi dalam tataran negaranasional, melainkan juga skala dunia.

Demokrasi radikal dalam skala dunia memungkinkan tidak adanya dominasi kepentingan dari segelintir negara pemegang kuasa kapital lebih.Dengan paradigma demokrasi radikal, politik global dapat terselenggara secara setara dan adil melalui rezim-rezim internasional yang dibentuk yang terdiri dari berbagai aspek, baik ekonomi pembangunan, budaya dan pengetahuan.

\section{DAFTAR PUSTAKA}

Anderson, B. (2016). Imagined communities. UK: Verso Books.

Appiah, K. A. (2010). Cosmopolitanism: Ethics in a World of Strangers. New\& London: W. W. Norton \& Company.

Archibugi, D. H. (1995). Cosmopolitan Democracy. An Agenda for a New World Order. Cambridge: Cambridge: Polity Press.

Brown, G. W. (2009). Grounding Cosmopolitanism From Kant to the Idea of a Cosmopolitan Constitution. Edinburgh: Edinburgh University Press Ltd. Derrida, J. (1997). Cosmopolitanism and Forgiveness. London and New York: Routledge. 
Held, D. (1995). Cosmopolitan Democracy and the Global Order: Reflections on the 200th Anniversary of Kant's "Perpetual Peace". Alternatives: Global, Local, Political, Vol. 20, No. $4 \quad$ (1995), $\quad 415-$ 429.https://doi.org/10.1177/03 0437549502000401

Held, D. (2001). The transformation of political community: rethinking democracy in the context of globalization. In I. S. HackerCordon, Democracy's Edges (pp. 84 - 111). New York: Cambridge University Press.

Mouffe, C. (2008). Which Order:

Cosmopolitan or Multipolar. Ethical Perspective 15 No.4, 453467.DOI:10.2143/EP.15.4.203439 1

Mouffe, C. (2009). Democracy in a Multipolar World. Millennium: Journal of International Studies Vol.37 No.3, pp. 549561.https://doi.org/10.1177/03 05829809103232

Mouffe, C. (2013). Democratic Citizenship and Political Community (1992). In J. Martin, Chantal Mouffe: Hegemony, radical democracy, and the political (pp. 103-114). London and New York: Routledge.

Nussbaum, M. C. (1997). Kant and Stoic Cosmopolitanism. The Journal of Political Philosophy vol.5 no.1 , 125.https://doi.org/10.1111/146 7-9760.00021

Sharp, J. B. (2004). Indigenous knowledges and development: a postcolonial caution. Third World Quarterly 25:4.https:// doi.org/10.1080/0 1436590410001678915
Smith, A. M. (1998). Laclau and Mouffe: The radical democratic imaginary. London and New York: Routledge.

Spivak, G. (2003). The Death of Discipline. New York USA: Columbia University Press.

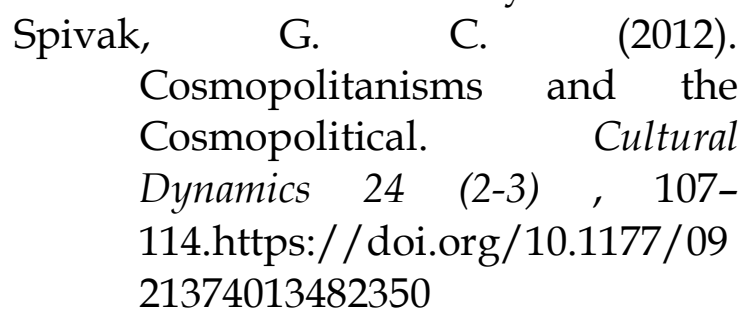

Trepanier, L. \&. (2011). Cosmopolitanism in the Age of Globalization: Citizens without States. Kentucky: University of Kentucky Press. 